\title{
Undifferentiated carcinoma of liver and intrahepatic biliary tract
}

INSERM

\section{Source}

INSERM. (1999). Orphanet: an online rare disease and orphan drug data base.

Undifferentiated carcinoma of liver and intrahepatic biliary tract. ORPHA:424970

Undifferentiated carcinoma of liver and intrahepatic biliary tract is an extremely rare epithelial tumor of the liver and biliary tract which presents heterogenous histological findings and not yet fully defined clinicopathological characterisitcs. Patients usually present with nonspecific signs and symptoms, such as abdominal pain, nausea, vomiting, anorexia, weight loss and/or jaundice. Invasive growth, hight metastatic potential and a rapid clinical course are typically associated. 